\title{
Adriana Mancini
}

\section{Héctor Tizón: la escritura y los avatares del exilio}

Palabras clave: exilio, nostalgia, memoria, ética, desarraigo

DOI: 10.4312/ars.11.2.168-177

\author{
[...] porque únicamente en caso \\ de tiranía es dable cambiar de patria. \\ Héctor Tizón $(1992,61)$
}

Desde sus comienzos, desde los primeros pasos para lograr la independencia de la futura Nación Argentina, luchas intestinas signaron el tenor del recorrido institucional. La generación del 37, jóvenes nacidos en la primera década del siglo XIX cuando la Revolución de Mayo de 1810 exaltaba los ánimos patriotas empeñados en cortar lazos con España, enfrentaban ideológicamente a los denominados «federales» cuyo conductor, Juan Manuel de Rosas, dominaba la rica y extensa región de la Provincia de Buenos Aires. El exilio fue el camino obligado de los disidentes al régimen rosista. Los países vecinos de Chile y Uruguay fueron refugio de Domingo Faustino Sarmiento y Esteban Echeverría, dos de los principales protagonistas de esta contienda. En el exilio, ambos escribieron dos textos fundantes de la literatura argentina: Facundo, una suerte de biografía del caudillo homónimo de la región de Cuyo y el Noroeste argentino de donde era originario Sarmiento y El matadero de Esteban Echeverría cuyo título, a través de una sinécdoque, refería a la situación de violencia que reinaba en la provincia de Buenos Aires. La intolerancia política, la persecución y muerte marcaron las décadas en la Argentina de forma sistemática hasta 1983, fecha en la que se recuperó la democracia. La literatura en sus variadas manifestaciones genéricas, particularmente narrativa y dramaturgia, dejaron un testimonio elocuente y verosímil de los hechos. Paradójicamente, la ficción tuvo a su cargo la verdadera historia; la contracara de la historia oficial que se difundía en épocas de gobiernos dictatoriales donde la censura imperaba. En el siglo XX y en particular durante la dictadura del último gobierno militar acaecida entre 1976 y 1983, los textos circulaban en forma clandestina y los escritores -aquellos que pudieron huir y salvaron su vida- escribieron desde el exterior. Esta vez, España y México fueron, entre otros, países que tendieron sus lazos solidarios; los países vecinos de Argentina, Chile, Uruguay, Paraguay, padecían sus respectivas dictaduras.

La novela de Ricardo Piglia, Respiración artificial (1980), sea el caso, pone en escena un personaje profesor de historia, a quien esperan infructuosamente; el profesor de historia no llega a una cita pautada (Piglia, 1980, 143, 272). Evidente primer indicio 
-en la ficción- de la innumerable cantidad de personas desaparecidas en Argentina en la década de los setenta. En El vuelo del Tigre (1981), de Daniel Moyano, la ficción da cuenta de un espacio invulnerable desde donde el poder controla sin eufemismos a una familia aterrada por la intrusión violenta de extraños en sus vidas. Harto elocuente, Moyano configura, en términos de Foucault, un panóptico vernáculo que, otra vez, por medio de una sinécdoque, alude a la situación política del país. En la novela La vida entera (2005) de Juan Martini se diseñan diversos espacios habitados por personajes signados socialmente en varios planos con respecto a un poder dominante. Hay marginales y prostitutas y un lugar central donde impera el horror controlado por «botas», que remiten retóricamente al calzado militar. Los ejemplos de las alusiones políticas esbozadas y, además, enmascaradas en recursos literarios que pretendieron sortear la censura, se multiplican y de cierta manera responden a la pregunta enunciada en Respiración artificial y proyectada hacia el futuro del tiempo ficcional de la novela, con la intención de denunciar un presente real de terror en el país: «A veces (no es joda) pienso que somos la generación del 37. Perdidos en la diáspora. ¿Quién de nosotros escribirá el Facundo?»(Piglia, 1980, 94, resaltados míos). Así, la sumatoria de textos que dejan rastros de ese período, podría considerarse ese «Facundo» pre-anunciado en la novela de Piglia.

Héctor Tizón fue uno de los intelectuales «perdidos en la diáspora» acaecida en la década del setenta. Su obra es extensa y valiosa; entre sus textos, el relato «Los árboles» y dos de sus novelas - La casa y el viento (1984) y El viejo soldado (2002)- escritos y publicados en distintas etapas de producción literaria dan cuenta de los avatares del exilio desde distintas perspectivas.

Oriundo de Jujuy, una provincia del norte argentino, limítrofe con Bolivia y Chile, Tizón nació en el año 1929 y murió en su tierra natal en 2012. Era abogado, fue juez en Jujuy, diplomático y un escritor atravesado por la belleza de una zona de esplendor geográfico. La Puna. Una tierra árida y soberbia que supo atrapar a sus hijos en la nostalgia cuando se alejan y en el dolor de la pobreza cuando permanecen en ella. Ambos motivos son rectores en gran parte de la narrativa de Tizón.

Afirma certera una voz de procedencia ambigua en la novela La casa y el viento:

Quien no recorra estas tierras jamás llegará a saber de qué manera el mundo, las cosas, son huidizos y frágiles. Estas rocas, los yacimientos desamparados, los ríos muertos como estelas geológicas. En ningún otro lugar como aquí, en la puna, pasa uno más fácilmente de la visión de lo aparente al ensueño (Tizon, 1984, 77).

Tanto para sus personajes anclados en ese paisaje dominante como para su creador, el desarraigo es una especie de condena; un camino de dolor sólo comparado con la 
muerte. Una muerte simbólica si el exiliado llega a destino o una muerte posible si el exiliado no logra cruzar la frontera. En este sentido, Sandra Lorenzano en un ensayo sobre la narrativa de Tizón, acierta al decir tomando como argumento las vicisitudes padecidas por Walter Benjamin en Port Bou al intentar cruzar la frontera camino a EEUU y en relación al personaje de La casa y el viento: «El viaje hacia la frontera será para todo exiliado un viaje en el filo de la muerte» (Lorenzano, 2001, 177).

En primera persona el personaje de La casa y el viento se propone narrar la despedida a su casa, y a su lugar natal mientras emprende el camino a la frontera. Un viaje que lo llevará hacia el norte de su terruño y que en parte se ensambla con el camino que recorrieron sus antepasados, el Camino del Inca, para seguir luego su destino hacia Europa. Así, el personaje de La casa y el viento reproduce un recorrido ancestral de los pueblos primitivos hacia el norte; pero también el camino invertido de los colonizadores españoles (Lorenzano, 2001, 177), en un movimiento que densifica la historia de los exilios y que necesita de las palabras que son el instrumento para fijar la memoria en la escritura del universo literario de Tizón.

Recordé otra vez lo que iba a dejar. Mi casa, edificada como quien planea su propia grandeza, mis perros, el secreto susurro de las hojas del parral en el patio, mi lugar de trabajo frente al fuego alimentado por esa leña cortada para muchos años y que no a toda vería arder. ¿La libertad acaso es no tener nada? ¿Y si, como sucede, también los verdugos y los violentos tuvieran razón? Mi ánimo se resquebraja como una tierra seca, pero quiero ser libre [...] (Tizón, 1984, 16-17).

La narración se autodefine como el «testimonio balbuceante de mi exilio» (Tizón, $1984,120)$ y si en cierto momento de la novela hay un reconocimiento de que todo lo que se escribe no es verdad, sino «retazos, trozos de la vida aparente, de mi vida y la de los otros» (Tizón, 1984, 83), se concluye de forma terminante que de esa manera es como se escribe la historia, o mejor, es la historia en general. Y la casa se resguarda en la memoria del personaje y de su creador, que podría considerarse su alter ego, a través de la escritura; dicho con precisión, se «significa» a través del arte.

Roland Barthes, en el ensayo «Proust y los nombres», afirma que la novedad en el pensamiento de Marcel Proust es «ubicar el lugar de lo imaginario en el signo» (Barthes, 1976, 188); es decir, en la relación del significado y el significante. Por consiguiente, el escritor no tendría como objetivo representar lo real sino significarlo.

En el relato «Los árboles», Tizón propone una puesta en escritura de la significación del exilio y de la muerte simbólica que esta situación trae consigo en un artista que descubre en tierra ajena una síntesis entre el paisaje de su tierra lejana y el de la tierra que lo acoge a partir de un árbol que logra pintar en su tela. Tiempo y espacio se 
superponen en la imagen que surge de sus pinceles que llegará a ser «Un árbol nuevo y semejante a algún árbol de mi infancia» (Tizón, 1992, 179).

En las notas que acompañan la edición de los relatos de El gallo blanco donde se compila «Los árboles», Tizón ofrece los pormenores de la génesis del cuento. La nota correspondiente está fechada en un mes determinado -febrero- sin que se señale un día preciso, ni el año. De esta manera el tiempo real se desestabiliza, ficcionalizándose. En la misma nota, el autor refiere a un viaje que él había realizado tiempo atrás cuyo objetivo habría sido encontrar los referentes de la obra de Van Gogh. Así, en los alrededores de Arlès, sólo recupera los «torturados árboles» de los manzanos en flor. A su vez, la nota que Tizón ofrece en la edición especifica que ese viaje original fue realizado en «días más felices» (Tizón, 1992, 193) que, intuimos, se contraponen a aquellos que se diseñan en el transcurso del relato «Los árboles» y que coinciden en el presente de su escritura. El recurso de Tizón se propone desdibujar los límites siempre borrosos entre ficción y realidad, recupera el presente de la escritura y en simultaneidad, el escritor se mimetiza con el personaje artista en el exilio del cuento para significar un árbol en la ficción:

Ahora, muchos años después, expatriado también yo, en las noches en blanco, escucho ladrar los perros de mi casa a miles de kilómetros de distancia. Estos datos, junto a otros que a nadie tal vez escaparán, conformaron la tierra propicia donde nació y creció el árbol de este cuento (Tizón, 1992, 193).

Una situación disímil, quizás de mayor densidad existencial, en tanto plantea una paradoja ética, surge de la novela El viejo soldado escrita antes que la novela La casa y el viento aunque publicada mucho después. Esta novela -El viejo soldado- incorpora la fecha de fin de escritura -febrero de 1981- y el lugar-Madrid- y las condiciones de producción -el exilio de su autor en esa ciudad-. Sin embargo, la novela fue editada por primera vez en junio de 2002 por la editorial Alfaguara en Buenos Aires y tuvo una reedición inmediata en agosto de 2002. Este dato puede analizarse desde dos perspectivas. En primer lugar, indica que los lectores se lanzaron de inmediato a la lectura de una obra silenciada largo tiempo, escrita por uno de los autores argentinos más prestigiosos. Pero al mismo tiempo, la novela pareciera no alcanzar el nivel literario que tienen otras novelas del autor, como Fuego en Casabindo (1969) o La mujer de Strasser (1997) o, incluso, La casa y el viento. Su autor reconocería la debilidad de esta novela al advertir que «Éste es, tal vez, el menos querido de mis libros, si ello fuera posible» (Tizón, 2002, 9). Sin embargo, a mi entender, es una de esas obras que sin ser acabada, perfecta en su resolución formal y con un motivo suficientemente expuesto en la ficción tal como el del exilio, plantea una situación ética no fácil de dirimir y que, casualmente, fue un tema polémico y no resuelto recuperado últimamente en la sociedad argentina ${ }^{1}$.

1 Me refiero a la discusión planteada recientemente (digo, a partir de los meses de mayo, junio de 2017) en el seno de la sociedad argentina, acerca de si a los presos condenados por delitos de lesa 
Asimismo, según escritores que han realizado su producción literaria fuera de su país natal, la condición de exiliado es favorable a la escritura. Ya sea por urgencias políticas o simplemente personales o incluso si se escribe desde el insilio. «Los más grandes escritores argentinos son exiliados, aún si jamás salieron de su lugar natal» (Saer, 1977, 279).

El libro El viejo soldado de Tizón se presenta con una cubierta cuyo diseño es un detalle de uno de los autorretratos del pintor argentino residente en París, Antonio Seguí ${ }^{2}$ quien además es uno de los destinatarios de las dedicatorias de la novela. El detalle enmarca una imagen del torso y el rostro de un hombre de rasgos adustos -hasta se diría, hoscos- resaltados por trazos gruesos en negro; color que rodea la cabeza y que contrasta con el rojo de su vestimenta y un rojo más intenso de una cruz que atraviesa su pecho desde los hombros hasta el borde inferior de la tapa del libro. El color arena rodea toda la figura y la resalta. Uno de los extremos de los trazos rojos de la cruz apunta a dos letras diseñadas en blanco que conforman la palabra «NO».

Lo interesante de esta figura es que después de leer la novela, se puede pensar que la imagen podría responder a cualquiera de sus dos protagonistas; tanto al viejo soldado, un viejo militar franquista retirado que desea escribir sus memorias y figura privilegiada por el título de la novela, como también al segundo personaje, el personaje escritor exiliado que busca y necesita trabajo, alguien que «agoniza» en segundo lugar en la contienda, desde la perspectiva de la etimología griega, un deuteroagonista. Pero dando un paso más, si se contempla la situación del autor de la novela, también exiliado, y la biografía del pintor al que se dedica el texto, un argentino residente en el exterior, y se relacionan ambas circunstancias con la primera dedicatoria del texto - «A Flora, mi mujer, cuyo amor y fortaleza me ayudaron a mantener la cabeza fuera del agua»- podemos sospechar que la imagen de la cubierta también representa a quien NO puede dejarse morir, tanto como a quien NO merece indulgencia por la culpa que sobreviene a causa de sus delitos.

A modo de prólogo de autor una Advertencia antecede el texto de El viejo soldado y, como en otros casos en la obra de Tizón estas notas amplían la perspectiva de lectura introduciendo lazos con el referente político social desencadenado por la última dictadura argentina. En esta Advertencia escrita para la edición de 2002 de la

humanidad les corresponderían los mismos derechos legales que a los presos comunes, incluso aquellos detenidos por delitos graves. Por ejemplo, la prisión domiciliaria a partir de los 70 años de edad (tal como cumpliría el ex presidente Carlos Menem recientemente condenado a siete años de prisión por la venta ilegal de armas durante su mandato) o la polémica ley llamada de 2X1 según la cual podrían reducirse los años de condena a la mitad si se cumplen determinados requisitos.

2 Es conocida la serie de pinturas de Seguí que representan a un personaje con vestimenta característica de los barrios de tango de la Ciudad de Buenos Aires, con un pie apoyado en el Obelisco de esta ciudad y otro en la Tour Eiffel de París. 
novela, el autor subraya que a pesar del consejo de amigos de no publicarla, consideró necesario dar a luz «este fruto amargo y balbuciente de una época de la que todos fuimos víctimas - a manos de los verdugos de siempre- de la crueldad, la estupidez, la falta de grandeza» (Tizón, 2002, 10).

Narrada en tercera persona, con focalización casi exclusiva en uno de sus personajes, el del joven escritor exiliado, con intervenciones de una voz de referencialidad incierta que podríamos atribuir a la intrusión del pensamiento del propio autor, la novela propone un argumento lineal. Un escritor militante de un país dominado por el terror con riesgo de ser detenido se refugia con su mujer y su pequeño hijo en Madrid. Allí pasa sus días buscando un trabajo que le permita salvar la jornada y mantener a su familia; añorando su vida en un «allá» que sabe irrecuperable o buscando sosiego en la mujer de un amigo a quien seduce. En varias ocasiones, acuciado por la falta de dinero, empeña objetos valiosos para sí. Ha intentado varios trabajos con nimio resultado hasta que decide vender su pluma al mejor postor. Anuncia en un periódico un aviso «Escritor profesional se ofrece para escribir o corregir manuscritos de carácter literario, autobiográficos o técnicos». La respuesta es inmediata. Un viejo soldado franquista solicita ayuda para escribir sus memorias; el joven escritor exiliado militante perseguido por la dictadura en su país se convierte de pronto en «el escriba de un viejo fascista» (Tizón, 2002, 71, 88).

La tarea no es sencilla; lentamente se van borroneando los límites de dos agonistas, aunque enfrenten ideas, posturas, ilusiones y años de dos generaciones que han vivido en épocas de contiendas irreconciliables. Las dictaduras opresivas no se discuten, pero los individuos que pertenecen a ambos bandos tienen sus fisuras. El viejo soldado es simpático, dadivoso y gentil con la familia del escritor a quien visita e invita a pasar unos días en su casa de campo. Sus muestras de afecto son reiteradas, pero no cesa en la demanda del escriba para completar sus memorias que en palabras inofensivas justifican bombardeos y atrocidades de la guerra. Por ejemplo:

Estábamos en la caída de Gijón ¿verdad? Repáselo usted ... La cantidad de prisioneros era tal que hubieron de habilitarse concentraciones [...] algunos muelles fueron alambrados [... ] En Oviedo pasaba otro tanto. Y en la costa donde yo accidentalmente me encontraba, puedo dar fe por conocimiento directo. Decenas de miles de vencidos pretendieron escapar embarcándose, milicianos y población civil, pero los barcos llenos de gente fueron hundidos ... Una verdadera tragedia vista desde lejos, ahora. [...] Pero, ¿qué le pasa a usted? Está pálido y ... (Tizón, 2002, 128-129).

El escritor va tornándose cada vez más irascible consigo y con la tarea que ha tenido que emprender. 
Es un viejo de mierda. [...] Lo que quiere es acomodar las cargas, quedar bien después de todo. Y yo hago de alcahuete; a sueldo, claro (101-102). Los fascistas sólo sirven de verdugos (120). [...] era llenarse las manos de mierda (136). Había comenzado a odiarlo (137). Ese asqueroso hijo de puta (146). Esto es una mierda pero hay que sobrevivir» (149). Lo escrito es también mío. Mutilado; quedaré mutilado. ¿Y él? (177).

Pero el texto de Tizón arma una paradoja desestimando la llamada teoría de los dos demonios. El joven va recorriendo un camino sinuoso de sucesivos momentos de identificación con su enemigo. La novela vira a un duelo en el que cada agonista lidia con un otro que se acerca cada vez más a sí mismo. Desde la primera visita, el joven escritor encuentra la casa del viejo franquista parecida a la de sus abuelos.

Solo faltaba allí el viejo gato, ronroneando nervioso o histérico sobre almohadones y cojines para recordarle por completo la vieja casa de sus abuelos, grande, umbría, impersonal, vagamente misteriosa y melancólica, unida en su memoria a velorios, castigos y silencios (89). Usted es igual que yo [dijo el viejo]. [Él] No podía admitir que ambos se parecieran en nada. Sí. - dijo el viejo soldado- Permítame decirlo. -Y esa fue una de las veces en que él, de pronto, creyó escuchar las mismas palabras e incluso ver los mismos gestos que su padre empleaba para hablarle (137). El viejo dijo enseguida: -Es curioso, no hace tanto que trabajamos juntos y creo que ya tengo algo de ti y me parece que tú lo tienes de mí (163).

Habría que notar que las similitudes entre el viejo soldado y su escriba son marcadas por el viejo mientras que las similitudes entre el viejo y su padre o las de ambas casas son establecidas por el escritor. Sin embargo, surge en él un recuerdo vergonzoso de su adolescencia que lo determina y saca de él lo peor de sí. La novela ahonda en el conflictivo interior del joven escritor hasta que él mismo reconoce:

[...] de qué manera atroz e involuntaria se habían identificado sin quererlo; un verdadero intruso que se había metido arteramente en su vida creándole un conflicto insoportable, y que luego de eso pretendía desaparecer, huir llevándose una parte de él mismo. ¿Pero acaso él no hizo siempre otro tanto? (184).

Como en todo duelo, la novela termina con la muerte de uno de sus dos agonistas. Pero a su vez, la muerte, la que da razón a la escritura, mata aquello otro que hay en uno mismo para alejarlo de sí. En este caso, la realidad estaría limitada a «lo blanco y negro» (Tizón, 2002, 187) y no a la vida convertida en un museo de las baratijas que colecciona el soldado y que el escritor considera tan muertas como muerto considera al viejo soldado. 
La identificación entre el viejo soldado, el joven escritor, el autor de la novela y la analogía entre las memorias de la guerra española y la novela de Tizón como testimonio «amargo y balbuciente de una época de la que todos fuimos víctimas» (Tizón, 2002, 10) no sólo corrobora la imagen que ilustra la cubierta del libro -el detalle de la obra de Seguí- que representa una figura que podría corresponderse con todos los elementos materiales de esta historia sino que confirma y actualiza el segundo epígrafe de la novela tomado de Shakespeare, Macbeth, IV, 3: Un relato tal vez elaborado en demasía pero cierto.

\section{Bibliografía}

AAVV., Ficción y Política. La narrativa argentina durante el proceso militar, Buenos Aires, Madrid 1987.

Barthes, R., Proust y los nombres, El grado cero de la escritura y otros ensayos, Buenos Aires 1976, pp. 171-190.

Foffani, E., Mancini, A., Más allá del regionalismo: la transformación del paisaje, en: Historia crítica de la literatura argentina, tomo 11 (ed. Jitrik, N.), Buenos Aires 2000, pp. 261-291.

Lorenzano, S., Escrituras de sobrevivencia. Narrativa argentina y dictadura, México 2001.

Mancini, A., Legitimidad y bastardía (sobre El gallo blanco de Héctor Tizón), Espacios 14, 1994.

Mancini, A., Juan José Saer: el exilio y la astucia, Lucera 7, Revista del Centro Cultural Parque de España, Rosario 2004.

Piglia, R., Respiración artificial, Buenos Aires 1980.

Principi, A., Derroteros de la escritura sobre La casa y el viento y El viejo soldado de Héctor Tizón, Orbis Tertius 8 (9), http://www.orbistertius.unlp.edu.ar/ [10. 6. 2017].

Saer, J. J., El concepto de ficción, Buenos Aires 1977.

Tizón, H., La casa y el viento, Buenos Aires 1984.

Tizón, H., Los árboles. El gallo blanco, Buenos Aires 1992, pp. 139-181.

Tizón, H., El viejo soldado, Buenos Aires 2002. 


\section{Adriana Mancini}

\section{Héctor Tizón: pisanje in spremembe izgnanstva}

Ključne besede: izgnanstvo, domotožje, spomin, etika, odtujenost

Izgnanstvo, posledica vrste zaporednih diktatur in totalitarnih vlad, ki prepredajo politično zgodovino Argentine, je zaznamovalo lokalno književnost, utrdilo njene zmožnosti prikazovanja resničnih dogodkov in ji naposled omogočilo, da povzdigne izzivalen glas, ki ustvarja napetost med uradnimi različicami. Avtorica si v članku prizadeva proučiti spremembe, ki izhajajo iz odtujenosti, cenzure in političnega preganjanja v nekaterih besedilih jujuyskega pisatelja Héctorja Tizóna. 


\section{Adriana Mancini}

\section{Héctor Tizón: writing and the avatars of exile}

Keywords: exile, nostalgia, memory, ethics, uprooting

The exile, as a consequence of successive dictatorships and totalitarian governments that crossed the political history of Argentina, has marked the vernacular literature, consolidating its power to signify the real facts until it conveys a defiant voice that stresses the official versions. In this article I intend to consider the avatars that arise from uprooting, censorship, and political persecution in some texts by the writer jujeño Héctor Tizón. 